\title{
Bulanık Uyarlanabilir Rezonans Teorisi (FuzzyART) Yöntemi Kullanılarak Heyelan Duyarlılık Analizi: Tonya (Trabzon) Örneği
}

\author{
Landslide Susceptibility Analysis by Fuzzy Adaptive Resonance Theory (FuzzyART) \\ Method: Tonya (Trabzon) Example
}

\author{
Aykut AKGÜN* \\ Karadeniz Teknik Üniversitesi, Mühendislik Fakültesi, Jeoloji Mühendisliği Bölümü, 61080, Trabzon
}

• Geliş tarihi / Received: 25.10.2017～• Düzeltilerek geliş tarihi / Received in revised form: 29.11.2017 • Kabul tarihi / Accepted: 04.12.2017

\begin{abstract}
$\ddot{O} z$
$\mathrm{Bu}$ çalışmada, şimdiye kadar heyelan duyarlılık analizi ile ilgili literatürde kullanılmamış olan bulanık uyarlanabilir rezonans teorisi (FuzzyART-BURT) olarak isimlendirilen ve esasında bir küme sınıflandırıcı olan yöntemin, heyelan duyarlılık haritası üretiminde kullanılması amaçlanmıştır. Bu amaç için, çalışma alanı olarak çoğunlukla sı ğ kayma yüzeyli heyelanların sıklıkla izlendiği ve bu nedenle geçmişten günümüze heyelan nedenli afet sürecine maruz kalan Trabzon iline bağlı Tonya ilçesi seçilmiştir. İlk olarak çalışma alanına ait, heyelan duyarlılık analizinde ihtiyaç duyulan hazırlayıcı nedenlerden litoloji, yükseklik, yamaç eğimi, yamaç yönelimi, akarsu güç indeksi (AGi) ve topoğrafik nemlilik indeksi (TNI) verileri elde edilmiştir. Alanda daha önceden meydana gelmiş ve geçmiş olay envanterini yansıtan heyelan envanter verisi çalışmada bağımlı değişken olarak kullanılmıştır. Elde edilen bu verilerden ilk olarak her bir hazırlayıcı parametre için frekans oranı değerleri hesaplanmış, hesaplanan bu frekans oranı değerlerinden itibaren her bir parametrede ayırt edilen alt sınıflar için duyarlılık sınıfları belirlenmiştir. Belirlenen bu duyarlılık sınıfları, uygulanan BURT yönteminde eğitim parametreleri olarak kullanılmıştır. BURT ile eğitilen her bir hazırlayıcı parametre verisinden o parametreye ait duyarlılık haritası üretildikten sonra, elde edilen tüm duyarlılık haritalarının bir araya toplanması sonucunda inceleme alanına ait nihai heyelan duyarlılık haritası elde edilmiştir. Üretilen sonuç heyelan duyarlılık haritasının doğruluk analizinin yapılabilmesi amacıyla, eğri altındaki alan (ROC-EAA) yöntemi kullanılmıştır. Yapılan doğrulama analizi sonucunda EAA değeri 0.72 olarak belirlenmiş olup bu değer üretilen heyelan duyarlılık haritasının oldukça başarılı bir kestirime sahip olduğunu göstermektedir.
\end{abstract}

Anahtar kelimeler: Doğal afet, Duyarlılık, Heyelan, Trabzon

\begin{abstract}
In this study, use of the method called as fuzzy adaptive resonance theory (FuzzyART) which is esentially a cluster classifier and has never been used in landslide susceptibility literature was aimed in producing of landslide susceptibility map. For this purpose, Tonya district belonging to Trabzon city where shallow seated landslides occasionally happens and exposed to several landslide-based hazards was chosen as study area. Initially, lithology, altitude, slope gradient, slope aspect, stream power index (SPI) and topographical wetness index (TWI) data belonging to the study area were chosen to be conditioning parameters needed for landslide susceptibility analysis. The landslide inventory data showing past case inventory was used to be independent parameter. From the conditioning parameters obtained, likelihood ratio (LR) values for each of these parameters were calculated, and based on the calculated LR values, susceptibility classes were determined for each of the sub-classes of the each parameters. These susceptibility classes were used as training parameter in the Fuzzy ART model applied. After obtaining the susceptibility maps of each parameter from each preliminary parameter database trained by FuzzyART, the final landslide susceptibility map of the study area was obtained as a result of the collection of all the susceptibility maps obtained. To perform the validation of the produced susceptibility map, area under curvature (AUC) method was used. At the end of the validation analysis, the AUC value was obtained to be 0.72, and this value shows that the susceptibility map produced has a good prediction capability.
\end{abstract}

Keywords: Natural hazard, Susceptibility, Landslide, Trabzon

*Aykut AKGÜN; aykutakgun@ gmail.com; Tel: (0462) 37735 08; orcid.org/0000-0001-5212-6447 


\section{Giriş}

Heyelanlar, dünyada depremlerden sonra en fazla meydana gelen ve bu nedenle de en çok can ve mal kaybına neden olan doğa olaylarından birisi olarak bilinmektedir (Ildır, 1995). Gerek ülkemizde, gerekse dünya genelinde heyelan nedenli afetlerin sayıs özellikle iklim değişikliğine bağlı gelişen aşırı yağışlar ve bazen de meydana gelen büyük depremlerin tetiklemesi sonucunda meydana gelmekte, çok sayıda can ve mal kaybını da beraberinde getirmektedir. Özellikle her türlü yer seçimi (yerleşim, depolama alanı, baraj yeri, vb.), güzergâh belirlenmesi (yol, demiryolu, enerji iletim hatt1 vb.) gibi mühendislik projelerinin gerçekleştirilmesi aşamasında proje alanının heyelan duyarlılığ açısından irdelenmesi ve gelecekte oluşabilecek heyelan nedenli problemlerin önceden kestirilerek gerekli önlemlerin alınmasına olanak tanınması noktasinda heyelan duyarlılık haritalarına olan gereksinim de son derece önem kazanmaktadır. Ülkemiz geneline bakıldığında gerek morfolojik yap1, gerek jeolojik birimlerin özellikleri ve gerekse de iklim koşulları nedeniyle heyelan nedenli afetlerin en çok yaşandığı alanlar Karadeniz Bölgesinin Doğu ve Batı Karadeniz bölümleri olarak görülmektedir. Son y1llarda Doğu Karadeniz Bölümünde aşırı yağışlara bağlı olarak gelişen sı̆̆ akma ve kaymalar neticesinde ciddi sayıda can ve mal kaybı ile karşılaşıldığı, bu nedenle de ciddi ekonomik kayıların meydana geldiği bilinmektedir.

Sözü edilen bu değerlendirmelerden yola çıkıldığında, gerek dünyada gerekse de ülkemizde heyelan duyarlılık değerlendirmeleri ile ilgili çalışmalar son yirmi yıldır önemli bir ivme kazanarak gelişmektedir. $\mathrm{Bu}$ alanda yapılan çalışmalara bakıldığında, ülkemizde çok sayıda araştırmacının, farklı parametreler, değişik değerlendirme yöntem ve süreçleri ile çok sayıda katk1 sağladığı söylenebilir (Gökçeoğlu ve Aksoy, 1996; Ercanoğlu ve Gökçeoğlu, 2002; Çevik ve Topal, 2003; Süzen ve Doyuran, 2004; Nefeslioğlu vd., 2008; Y1lmaz, 2009; Dağ vd., 2011; Demir vd., 2013; Kavzoğlu vd., 2014; Eker vd.,2015; Erener vd., 2016; Akgün ve Erkan, 2016; Gurocak vd., 2017).

Heyelan duyarlılık amaçlı yapılan çalışmalarda, kullanılan parametrelerin seçimi daha çok çalışma alanındaki heyelanların gelişim sürecini önemli ölçüde denetleyen parametrelere gözetilerek seçilirken (Gökçeoğlu ve Ercanoğlu, 2001), bu parametrelerin değerlendirilmesinde ise esas olarak dört yöntem grubunda yer alan yaklaşımlardan yararlanılmıştır. Bu yaklaşımlar: a) deterministik (Carrara vd., 1995; Guzetti vd., 1999; Chacon vd., 2006; Thiebes, 2011; Akgün ve Erkan, 2016), b) sezgisel (Castellanos Abella ve Van Westen 2007; Akgün 2012; Nefeslioglu vd., 2013; Roodposhti vd., 2013 ), c) istatistiksel (Süzen ve Doyuran, 2004; Çan vd., 2005; Akgün ve Bulut 2007; Nefeslioğlu vd., 2008; Kıncal vd., 2009; Pradhan vd. 2010; Sezer, vd., 2011; Althuwaynee vd., 2012; Akgün vd., 2012; Ösna vd., 2014) ve d) heyelan envanterine dayalı olasılıksal yaklaşımlar (Sezer vd., 2011; Akgün vd., 2011; Pradhan, 2011; Melchiorre, vd., 2011) olarak bilinmektedir. Bu yöntemler içerisinde yer alan ve yöntemin yapısal özellikleri gereği hem sezgisel, hem de olasılıksal olarak gruplandırılabilecek veri madenciliği ve esnek hesaplama yaklaşımları olan yöntemlerde (yapay sinir ağları, karar ağacı, genetik algoritma, bulanık çıkarsama sistemleri, destek vektör makinaları) son on yıldır sıklıkla kullanılmakta olan yöntemler arasında yer almaktadır (Akgün vd., 2012; Nefeslioğlu vd., 2010; Ercanoglu vd., 2016; Romer ve Ferentinou, 2016; Çölkesen vd., 2016).

Bu çalışmada da, yapay sinir ağları ile bulanık mantık yaklaşımlarını birleştiren bir yöntem olan ve Fuzzy ARTMAP olarak literatürde isimlendirilen bulanık uyarlanabilir rezonans teorisi (BURT) kullanılarak bir heyelan duyarlılık haritası üretilmesi amaçlanmıştır. $\mathrm{Bu}$ amaçla, IDRISI Selva V17.0 Coğrafi Bilgi Sistemleri (CBS) ve Uzaktan Algilama (UA) yazılımındaki arayüz uygulaması kullanılmıştır. $\mathrm{Bu}$ yöntem, literatürde heyelan duyarlılık haritalaması için ilk kez kullanılmıştır.

\section{2. Çalışma Alanı ve Jeolojisi}

Bu çalışmada inceleme alanı olarak Trabzon iline bağl1, Tonya ilçesi seçilmiştir. Tonya ilçesi, Trabzon il sınırları içerisinde heyelan olaylarından en fazla etkilenen ilçelerin başında gelmektedir (Şekil 1). İlçede topoğrafyanın oldukça sarp, yüzeylenen litolojik birimlerin oldukça ayrışmış ve yıllık ortalama yağış değerinin $2200 \mathrm{~mm}$ civarında (URL-1) olması nedeniyle saha gerek sığ ve derin heyelanların, gerekse de kaya düşmesi türünden kütle hareketlerinin gelişmesine son derece açıktır.

Çalışma alanında yüzeylenen birimler, çoğunlukla volkanik ve volkano-klastik birimler olarak ayırt edilmektedir. Bu birimlerin yaşı Jura' dan başlayıp Geç Kretase ile devam eden ve Eosen ile sonlanan bir sıralanma sunmaktadır (MTA, 1998) (Şekil 2). 


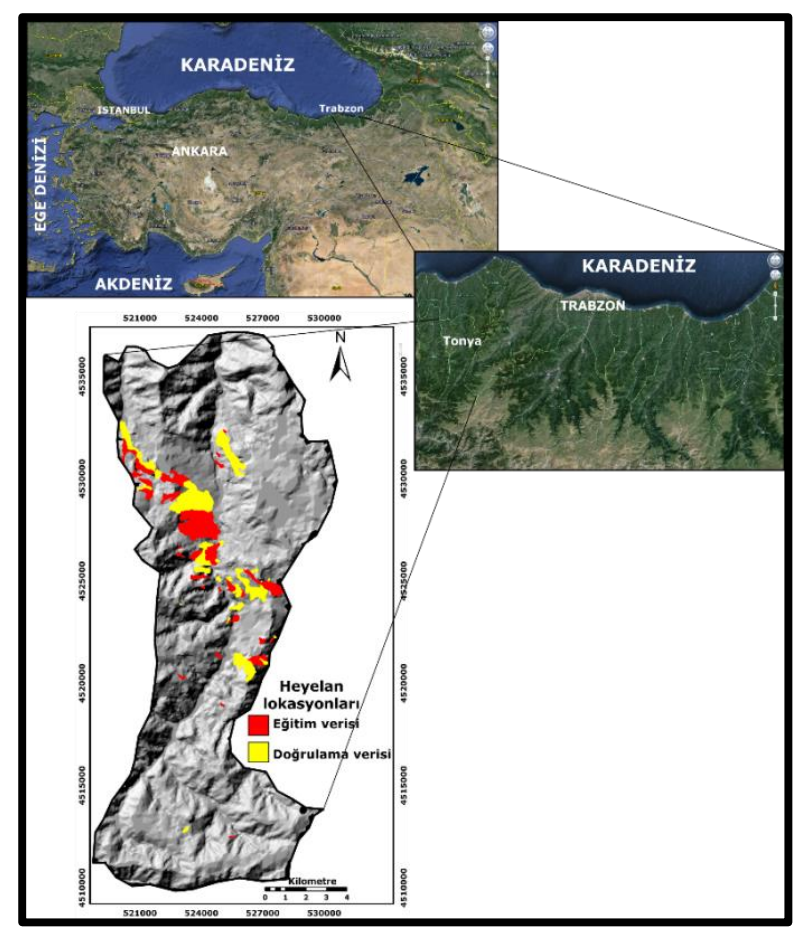

Şekil 1. İnceleme alanına ait lokasyon haritası

Alanda Eosen yaşlı birimler bazalt, andezit ve piroklastlarından oluşan, yer yer kumlu kireçtaş1 ara katkılarından oluşan (Ev) ile gösterilen birimler ile (Gama2) olarak simgelenen granit, granodiyorit, kuvars diyorit ve dolerit karakterinde litolojilerle temsil edilmektedir (Şekil 2). Geç Kretase yaşlı birimler (Kru1, Kru2, Kru3, Kru4b, Kru5a) bazalt, andezit, dasit, riyodasit ve piroklastlarından oluşurken, (Kru5b) kumlu resifal kireçtaşı birimi olarak ayırtlanmaktadır (Şekil 2). En yaşı ı birim olarak Liyas-Dogger yaşli bazalt, andezit, dasit ve piroklastları sahada yüzlek vermektedir. Bu birimlerin alansal dağılımına bakıldığında yaklaşık \%35'lik oranla (Ev) birimleri başı çekmektedir. Gerek volkanik ve volkano-klastik birimler, gerekse de intrüzif birimler yüksek derecede ayrışmış olup, ayrışma kalınlığı yer yer 5-10 $\mathrm{m}$ arasında değişim göstermektedir. $\mathrm{Bu}$ değişim, beraberinde sı̆̆ akma ve kaymalara da hazırlayıcı ortam sunmaktadır.

\section{Materyal ve Yöntem}

$\mathrm{Bu}$ çalışmada, inceleme alanına ait heyelan duyarlılık haritasının hazırlanması amaciyla, alanda heyelan gelişimini baskın olarak denetlediği gözlenen litoloji, yamaç eğimi, yamaç yönelimi, akarsu güç indeksi (AGI) ve topoğrafik nemlilik indeksi parametreleri kullanılmıştır.

$\mathrm{Bu}$ amaçla, alana ait 1:100.000 ölçekli Maden Tetkik ve Arama Genel Müdürlüğü (MTA) (1998) tarafindan hazırlanan jeoloji haritası ArcGIS 10.0
CBS yazılımı kullanılarak vektör veri formatında sayısallaştırılmış, daha sonra mekânsal çözünürlüğü $25 \mathrm{~m}$ olan raster veri formatına dönüştürülmüştür.

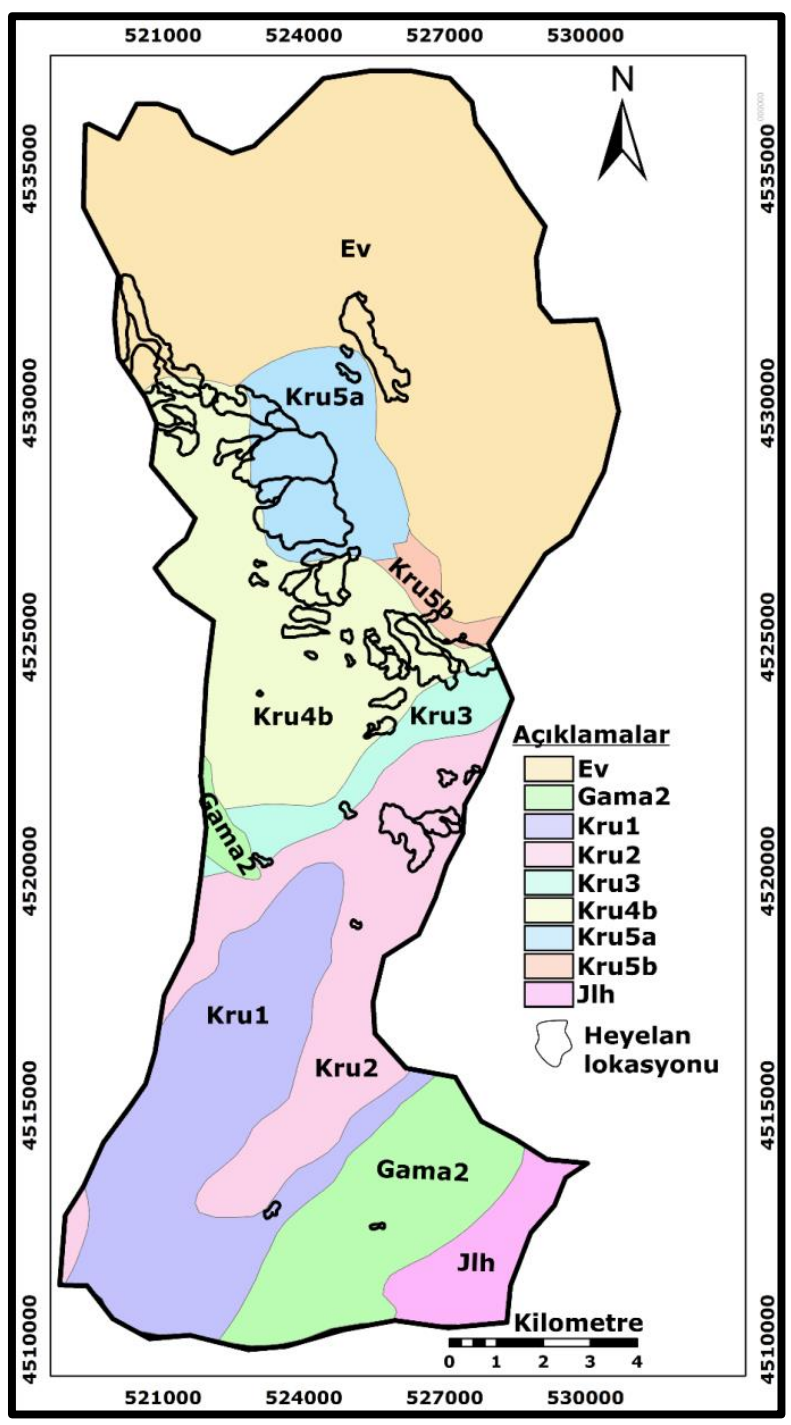

Şekil 2. İnceleme alanına ait litoloji haritası.

USGS (1993)'e göre 1:25.000 ölçekli haritalarda konumsal doğruluk gereği mekânsal çözünürlüğün $\pm 12.5 \mathrm{~m}$ olması önerilmektedir. Buna karşın literatürde bu konuda bir görüş birliği de bulunmamakta olup, çalışma alanındaki heyelanların 1.25.000 ölçekte haritalanabilir olmaları alansal olarak 25 m mekânsal çözünürlükle gösterilebilmelerini olanaklı kılmaktadır. Alana ait ve Harita Genel Komutanlığ1 tarafindan hazırlanan 1:25.000 ölçekli topoğrafik harita üzerinden eş yükseklik eğrileri $10 \mathrm{~m}$ 'de bir olmak üzere vektör veri formatında sayısallaştırılmış ve sayısal topoğrafik veri üretilmiştir. Üretilen bu sayısal topoğrafik veri üzerinden $25 \mathrm{~m}$ mekansal çözünürlüğe sahip sayısal yükseklik modeli (SYM) elde edilmiştir. 
Elde edilen SYM'den itibaren yükseklik değeri, yamaç eğim, yamaç yönelimi, AGİ (Moore vd.,1991) ve TNI (Moore vd., 1991) haritalar1 yine raster veri formatında ve $25 \mathrm{~m}$ mekânsal çözünürlüğe sahip olarak üretilmiştir.

Çalışmada bağımlı değişken olarak değerlendirilen ve eğitim alanlarının oluşturulmasında kullanılan heyelan envanter verisi için Duman vd. (2007) tarafindan üretilen 1:25.000 ölçekli Türkiye Heyelan Envanter Verisinden yararlanılmışır. $\mathrm{Bu}$ haritada, alanda meydana gelmiş heyelanlar zaman bilgisinden yoksun olarak yalnızca mekânsal alan belirteci şeklinde gösterilmektedir. Vektör veri formatında hazırlanmış bu haritadan çalışma alanındaki heyelanlar $25 \mathrm{~m}$ mekânsal çözünürlüğe sahip olacak şekilde raster formatına dönüştürülmüştür. Alanda tanımlanmış heyelanlar aktivitelerine göre "aktif" ve "eski" heyelan olarak ayırt edilmiştir. Söz konusu heyelanların hemen hemen tamamına yakını Varnes (1978) sinıflandırmasına göre sığ düzlemsel kayma ve akma niteliği göstermektedir. Heyelan envanter verisine dayalı duyarlılık analiz modellerinde, envanter verisinin modeldeki örneklem modelleri literatürde farkl111klar göstermektedir (Süzen ve Doyuran 2004; Nefeslioğlu vd. 2008; Y1lmaz 2010; Dağdelenler vd. 2015; Akgün ve Erkan, 2016).

$\mathrm{Bu}$ çalışmalarda, envanter verisi kullanılırken kayan kütlenin hareket etmemiş olan bölgesinden itibaren geriye doğru belirli bir mesafede oluşturulacak bir tampon bölgenin modele katılması, birikim zonu olarak adlanan kütlenin ise örneklem dışı bırakılması önerilmektedir. Buna karşın, tüm kütlenin de örneklem verisi olarak kullanılabildiği ifade edilmektedir. Bundan dolayı, bu çalışmada envanter verisi örneklem sürecinde kütlenin bütünü alınarak modelleme çalışması gerçekleştirilmiştir.

Carpenter vd. (1991) tarafindan sinir ağlarına dayandırılmış "Uyarlanabilir rezonans teorisi" (URT) biyolojik kavramsal bilgi işleme teorisinden evrilmiş bir yöntemdir. URT yöntemi, özellikle duraylılık-plastisite ikilemini çözmek, önemsenir geçmiş öğrenmeyi önleme ve fakat herhangi bir zamanda ortaya çıkabilen yeni bilginin eski bilgiyle entegre olması için yeterince uyarlanabilir kalmasını sağlamak için yüksek derecede bir duraylılık sağlamayı amaçlar (Carpenter, 1989). URT modellerinin geniş bir tanımı ve bu konuda kavramsal yaklaşımlara yönelik detay bilgiler Carpenter vd. (1991), Carpenter vd. (1992) ve Mannan vd. (1998) de bulunabilir.
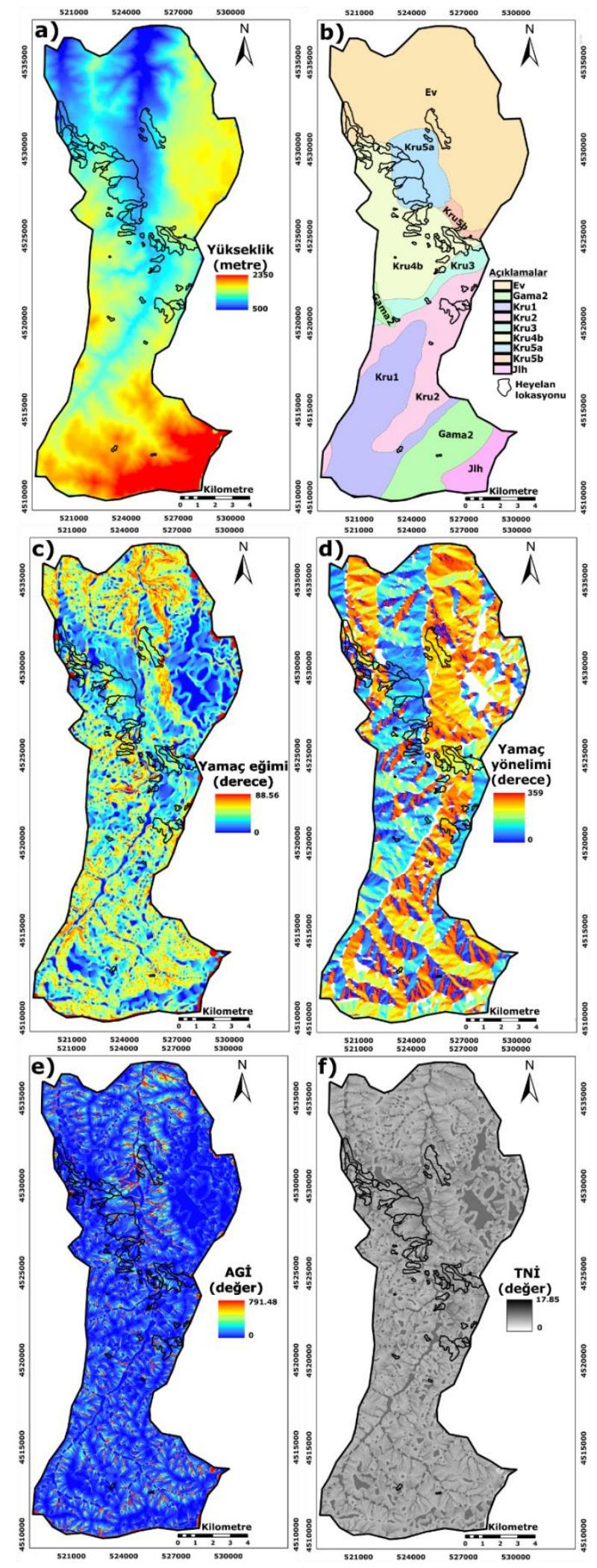

Şekil 3. Heyelan duyarlı1ık değerlendirmesinde kullanılan hazırlayıcı parametreler: a)Yükseklik, b) Litoloji, c) Yamaç eğimi, d) Yamaç yönelimi, e) AGİ, f) TNI.

Carpenter vd. (1992), BURT yaklaşımını bulanık analog girdi desenli (0-1 arası gerçel sayılar) vektörleri yöneten ve daha önce öğrenilmiş durumları unutmaksızın sürekli olarak öğrenmeye 
izin vererek bu vektörleri birleştiren bir kümeleme (sınıflandırma) algoritması olarak tanımlamıştır. BURT yaklaşımı hem denetimsiz hem de denetimli veri sınıflandırma özelliği olan bir mimariye sahiptir. $\mathrm{Bu}$ çalışmada, BURT yaklaşımının denetimli sınıflandırma özelliğinden yararlanılmıştır.

BURT yaklaşımına ait mimari Şekil 4'de sunulmuştur. Denetimsiz sinıflandırmada, F1 (girdi) ve F2 (kategori) olmak üzere iki tabaka yer almaktadır. $\mathrm{Bu}$ iki tabaka URTa modelini oluşturur. F1 tabakası girdi nitelik vektörlerini temsil etmekte ve dolayısıyla her ölçüm boyutunda nöronlara sahip olmaktadır. BURT yaklaşımı, n-boyutlu girdi vektörleri aşağıda verilen eşitlik (1)'e işlenebilsin diye ikinci bir girdi boyutuna sahiptir.

$\mathrm{I}=\left(\mathrm{a}, \mathrm{a}^{\mathrm{c}}\right)^{=(\mathrm{a} 1, \mathrm{a} 2, \ldots \mathrm{an}, 1-\mathrm{a} 2, \ldots . ., 1-\mathrm{an})}$

F2 tabakasındaki nöronlar otomatik olarak belirlenebilir. Diğer bir ifadeyle F2 tabakası tek bir nöronla başlar ve öğrenme işlemi boyunca dinamik olarak büyür.

Denetimli siniflandirmada, denetimsiz siniflandirmadan farklı olarak ilave iki tabaka daha bulunur. Bunlar "harita alan" ve "çıtı" tabakalanıdır. $\mathrm{Bu}$ iki tabaka URTb modelini oluşturur. Çıktı ve harita alan tabakalarının her biri " $\mathrm{m}$ " nöronlarından oluşmakta olup burada $\mathrm{m}$ çıktı sınıfının boyutunu ifade etmektedir. Bu her iki tabaka arasında bire bir bir bağlantı mevcuttur (Şekil 4).

Yukarıda kavramsal bilgisi verilen BURT modeli uygulanmadan önce, çalışma alanı için üretilen hazırlayıcı nedenler ve heyelan envanter verisi kullanılarak her bir hazırlayıcı faktör ve bu faktörler altında ayırt edilmiş alt sınıflara ait benzerlik oranı (BO) (Lee vd., 2004) değerleri hesaplanıştır. BO yöntemi, kısaca belirli bir doğal olayın (heyelan) meydana gelmesinin, aynı olayın meydana gelmemesine oranının olasılığını ifade etmektedir. Eğer benzerlik oranı 1'den büyük olursa, heyelan ve heyelana neden olan parametre arasındaki ilişki o kadar yüksek, tersine, 1'den ne kadar küçük olursa bu ilişki o kadar düşük olacaktır (Akgün ve Türk, 2010). Bu kapsamda elde edilen BO değerleri aşağıda Tablo 1'de verilmiş̧ir.

Elde edilen BO değerleri kullanılarak hazırlayıcı parametre haritaları yeniden sınıflandırılmış ve BO değerine göre sınıflandırılmış parametre haritaları üretilmiştir.

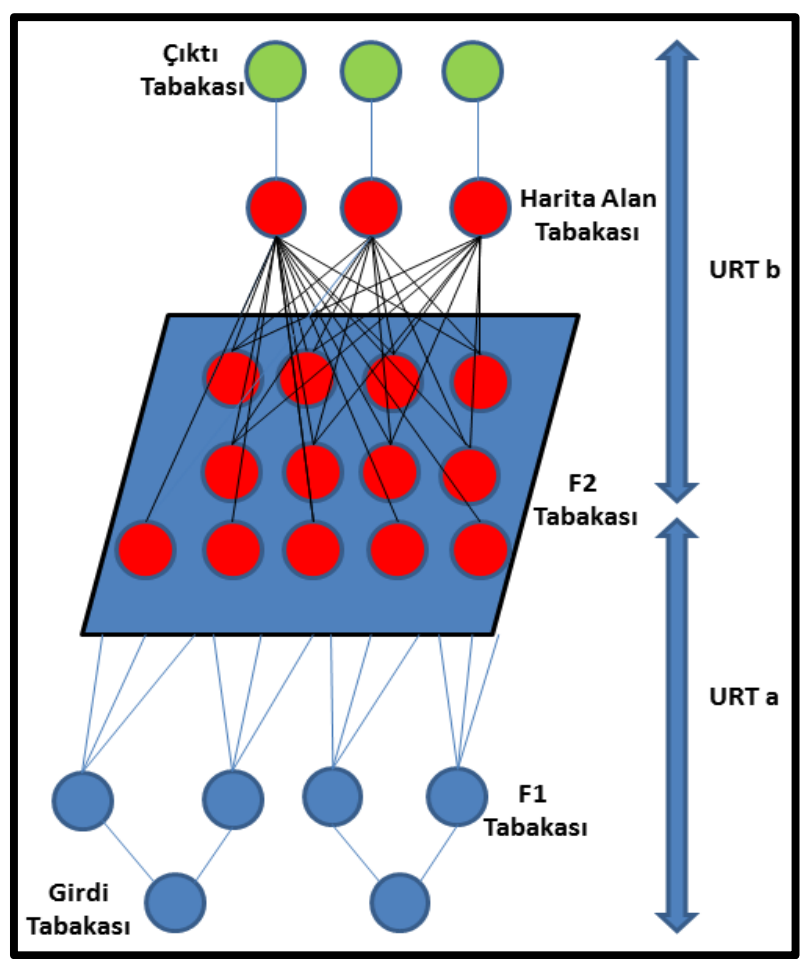

Şekil 4. Heyelan duyarlılık modellemesinde kullanılan BURT yaklaşımına ait mimari.

BO değerlerinin yüksek olduğu alanlar doğal olarak heyelan duyarlılığının yüksek, BO değerinin düşük olduğu yerler ise heyelan duyarlılığının düşük olduğunu ifade etmektedir. Bu durum dikkate alındığında, Tablo 1'de verilen BO değerleri 1 ile 5 arasında olmak üzere 1 "Çok düşük", 5 "çok yüksek" duyarlılığı temsil edecek şekilde normalize edilmiştir. Normalize edilmiş değerler kullanılarak BO değerine göre yeninden sınıflandırılmış haritalar tekrar bir sınıflandırmaya tabi tutulmuştur.

Böylelikle, BO değerlerinden itibaren her bir hazırlayıcı parametre için bir heyelan duyarlılık haritası elde edilmiştir. Elde edilen bu her bir parametre tabanlı duyarlılık haritası BURT modelinde bir eğitim seti, diğer hazırlayıcı parametreler ise girdi verisi olarak kullanılmıştır.

Bu kapsamda, 6 hazırlayıcı parametre haritasının her birinden üretilen sinıflandirma setleri ve bu seti temsil eden parametre dışındaki diğer 5 parametre girdi verisi olarak kullanılmak üzere 6 duyarlılık haritası elde edilmiştir. Sözü edilen bu yönteme ait akış diyagramı Şekil 5'de verilmiştir.

Elde edilen 6 duyarlılık haritası aritmetik olarak toplanmak suretiyle de inceleme alanına ait sonuç heyelan duyarlılık haritası üretilmiştir (Şekil 6). 
Tablo 1. Benzerlik oranı değerleri ve karşılık gelen duyarlılık sınıfları.

\begin{tabular}{|c|c|c|c|c|c|c|}
\hline $\begin{array}{l}\text { Yamaç yönelimi } \\
\text { (derece) }\end{array}$ & \multicolumn{2}{|c|}{ HEYELANSIZ PİKSELLER } & \multicolumn{2}{|c|}{$\begin{array}{l}\text { HEYELANLI } \\
\text { PİKSELLER }\end{array}$} & & \\
\hline SINIF & Piksel sayısı & $\begin{array}{l}\text { \% Piksel } \\
\text { (a) }\end{array}$ & $\begin{array}{l}\text { Piksel } \\
\text { sayısı }\end{array}$ & $\begin{array}{l}\text { \% Piksel } \\
\text { (b) }\end{array}$ & $\begin{array}{c}\text { BO değeri } \\
\text { (b/a) }\end{array}$ & $\begin{array}{l}\text { Duyarlılık } \\
\text { Sinıfları }\end{array}$ \\
\hline Düz & 69855 & 21.60 & 2498 & 22.94 & 1.06 & 3 \\
\hline $0-45$ & 31409 & 9.71 & 2451 & 22.51 & 2.32 & 5 \\
\hline $45-90$ & 34071 & 10.53 & 1988 & 18.26 & 1.73 & 4 \\
\hline $90-135$ & 22391 & 6.92 & 891 & 8.18 & 1.18 & 3 \\
\hline $135-180$ & 18755 & 5.80 & 468 & 4.30 & 0.74 & 2 \\
\hline $180-225$ & 25222 & 7.80 & 535 & 4.91 & 0.63 & 2 \\
\hline $225-270$ & 45228 & 13.98 & 964 & 8.85 & 0.63 & 2 \\
\hline $270-315$ & 41475 & 12.82 & 528 & 4.85 & 0.38 & 1 \\
\hline $315-359$ & 35094 & 10.85 & 565 & 5.19 & 0.48 & 2 \\
\hline Toplam & 323500 & 100.01 & 10888 & 100.00 & & \\
\hline $\begin{array}{l}\text { Yamaç eğimi } \\
\text { (derece) }\end{array}$ & \multicolumn{2}{|c|}{ HEYELANSIZ PİKSELLER } & \multicolumn{2}{|c|}{$\begin{array}{l}\text { HEYELANLI } \\
\text { PİKSELLER }\end{array}$} & & \\
\hline SINIF & Piksel sayısı & \% Piksel & $\begin{array}{l}\text { Piksel } \\
\text { sayısI }\end{array}$ & \% Piksel & BO değeri & $\begin{array}{l}\text { Duyarlılık } \\
\text { Sinıfları }\end{array}$ \\
\hline $0-10$ & 67076 & 20.73 & 2201 & 20.21 & 0.97 & 4 \\
\hline $10-20$ & 92685 & 28.65 & 4629 & 42.51 & 1.48 & 5 \\
\hline $20-30$ & 100987 & 31.22 & 2851 & 26.18 & 0.84 & 3 \\
\hline $30-40$ & 49827 & 15.40 & 940 & 8.63 & 0.56 & 2 \\
\hline $40-50$ & 7500 & 2.32 & 197 & 1.81 & 0.78 & 3 \\
\hline $50-60$ & 5425 & 1.68 & 70 & 0.64 & 0.38 & 1 \\
\hline Toplam & 323500 & 100.00 & 10888 & 100.00 & & \\
\hline TNI & \multicolumn{2}{|c|}{ HEYELANSIZ PİKSELLER } & \multicolumn{2}{|c|}{$\begin{array}{l}\text { HEYELANLI } \\
\text { PİKSELLER }\end{array}$} & & \\
\hline SINIF & Piksel sayısı & \% Piksel & $\begin{array}{l}\text { Piksel } \\
\text { sayısı }\end{array}$ & \% Piksel & BO değeri & $\begin{array}{l}\text { Duyarlılık } \\
\text { Sinffları }\end{array}$ \\
\hline $0-4$ & 4960 & 1.53 & 95 & 0.87 & 0.57 & 1 \\
\hline $4 \_8$ & 233520 & 72.19 & 7557 & 69.41 & 0.96 & 2 \\
\hline 8_12 & 78258 & 24.19 & 2979 & 27.36 & 1.13 & 4 \\
\hline $12 \_16$ & 6019 & 1.86 & 226 & 2.08 & 1.12 & 3 \\
\hline$>16$ & 743 & 0.23 & 31 & 0.28 & 1.24 & 5 \\
\hline Toplam & 323500 & 100.00 & 10888 & 100.00 & & \\
\hline
\end{tabular}


Tablo 1'in devamı

\begin{tabular}{|c|c|c|c|c|c|c|}
\hline AGİ & \multicolumn{2}{|c|}{ HEYELANSIZ PİKSELLER } & \multicolumn{2}{|c|}{$\begin{array}{l}\text { HEYELANLI } \\
\text { PİKSELLER }\end{array}$} & & \\
\hline SINIF & Piksel sayısı & \% Piksel & $\begin{array}{l}\text { Piksel } \\
\text { sayısı }\end{array}$ & \% Piksel & BO değeri & $\begin{array}{l}\text { Duyarlılık } \\
\text { Sinıfları }\end{array}$ \\
\hline $0-150$ & 252187 & 77.96 & 8988 & 82.55 & 1.06 & 5 \\
\hline $150-300$ & 38875 & 12.02 & 1144 & 10.51 & 0.87 & 4 \\
\hline $300-450$ & 11267 & 3.48 & 246 & 2.26 & 0.65 & 1 \\
\hline $450-600$ & 5500 & 1.70 & 132 & 1.21 & 0.71 & 2 \\
\hline $600-750$ & 3132 & 0.97 & 68 & 0.62 & 0.65 & 1 \\
\hline$>750$ & 12539 & 3.88 & 310 & 2.85 & 0.73 & 3 \\
\hline Toplam & 323500 & 100.00 & 10888 & 100.00 & & \\
\hline Litoloji & \multicolumn{2}{|c|}{ HEYELANSIZ PİKSELLER } & \multicolumn{2}{|c|}{$\begin{array}{l}\text { HEYELANLI } \\
\text { PÍKSELLER }\end{array}$} & & \\
\hline SINIF & Piksel sayısı & \% Piksel & $\begin{array}{l}\text { Piksel } \\
\text { sayısi }\end{array}$ & \%Piksel & BO değeri & $\begin{array}{l}\text { Duyarlılık } \\
\text { Sinıfları }\end{array}$ \\
\hline Kru1 & 48574 & 15.05 & 0 & 0.00 & 0.00 & 1 \\
\hline Kru5 & 3363 & 1.04 & 78 & 0.72 & 0.69 & 2 \\
\hline Kru5a & 19904 & 6.17 & 4208 & 38.65 & 6.27 & 5 \\
\hline Gama2 & 29644 & 9.18 & 43 & 0.39 & 0.04 & 1 \\
\hline Jlh & 10471 & 3.24 & 0 & 0.00 & 0.00 & 1 \\
\hline Kru3a & 299 & 0.09 & 0 & 0.00 & 0.00 & 1 \\
\hline Kru4b & 48430 & 15.01 & 4751 & 43.64 & 2.91 & 4 \\
\hline Kru2 & 38281 & 11.86 & 774 & 7.11 & 0.60 & 2 \\
\hline Kru3 & 9246 & 2.86 & 371 & 3.41 & 1.19 & 3 \\
\hline Ev & 115288 & 35.72 & 663 & 6.09 & 0.17 & 2 \\
\hline Toplam & 323500 & 100.23 & 10888 & 100.00 & & \\
\hline Yükseklik (m) & \multicolumn{2}{|c|}{ HEYELANSIZ PİKSELLER } & \multicolumn{2}{|c|}{$\begin{array}{l}\text { HEYELANLI } \\
\text { PİKSELLER }\end{array}$} & & \\
\hline SINIF & Piksel sayısı & $\%$ Piksel & $\begin{array}{l}\text { Piksel } \\
\text { sayısı }\end{array}$ & \% Piksel & BO değeri & $\begin{array}{l}\text { Duyarlılık } \\
\text { Sinıfları }\end{array}$ \\
\hline $0-250$ & 3988 & 1.23 & 9 & 0.08 & 0.07 & 2 \\
\hline $250-500$ & 16526 & 5.11 & 126 & 1.16 & 0.23 & 3 \\
\hline $500-750$ & 42565 & 13.16 & 3337 & 30.65 & 2.33 & 5 \\
\hline $750-1000$ & 69037 & 21.34 & 4994 & 45.87 & 2.15 & 4 \\
\hline $1000-1250$ & 76413 & 23.62 & 2347 & 21.56 & 0.91 & 3 \\
\hline $1250-1500$ & 61816 & 19.11 & 32 & 0.29 & 0.02 & 1 \\
\hline $1500-1750$ & 27932 & 8.64 & 43 & 0.39 & 0.05 & 1 \\
\hline $1750-2000$ & 12972 & 4.01 & 0 & 0.00 & 0.00 & 1 \\
\hline$>2000$ & 12251 & 3.79 & 0 & 0.00 & 0.00 & 1 \\
\hline Toplam & 323500 & 100.01 & 10888 & 100 & & \\
\hline
\end{tabular}




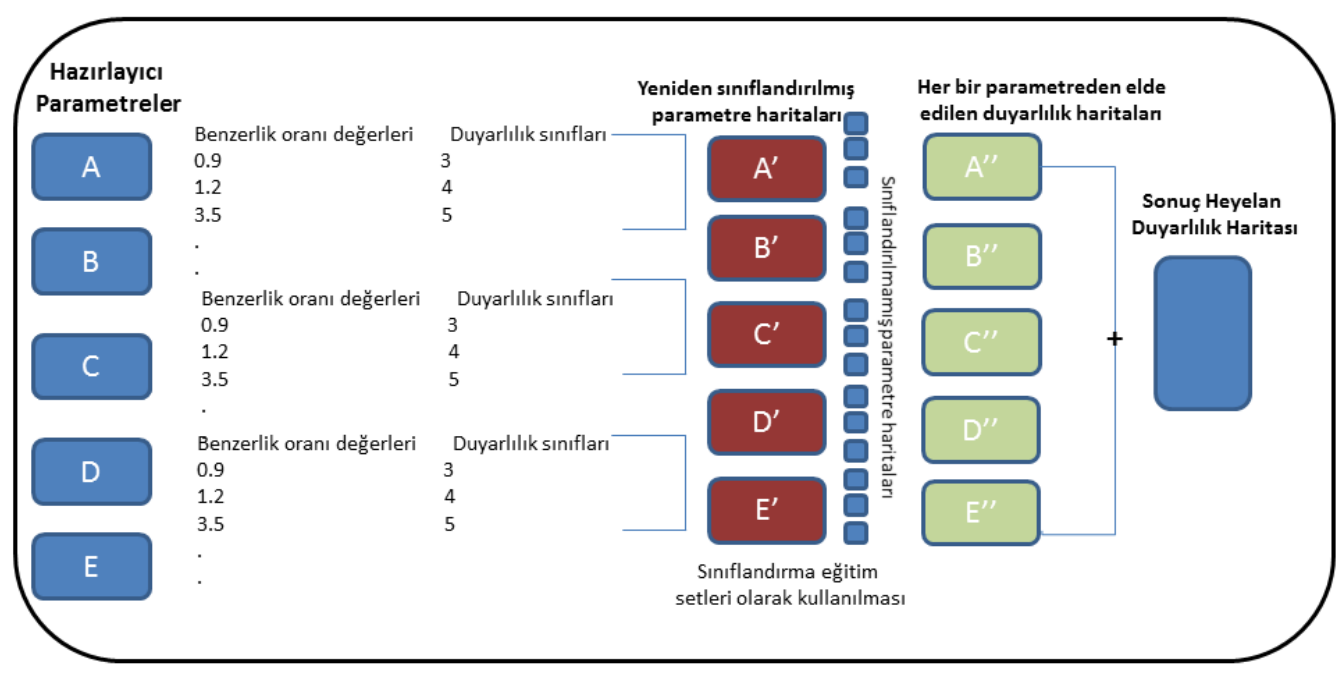

Şekil 5. Bu çalışmada önerilen duyarlılık haritalama modeline ait akış diyagramı.

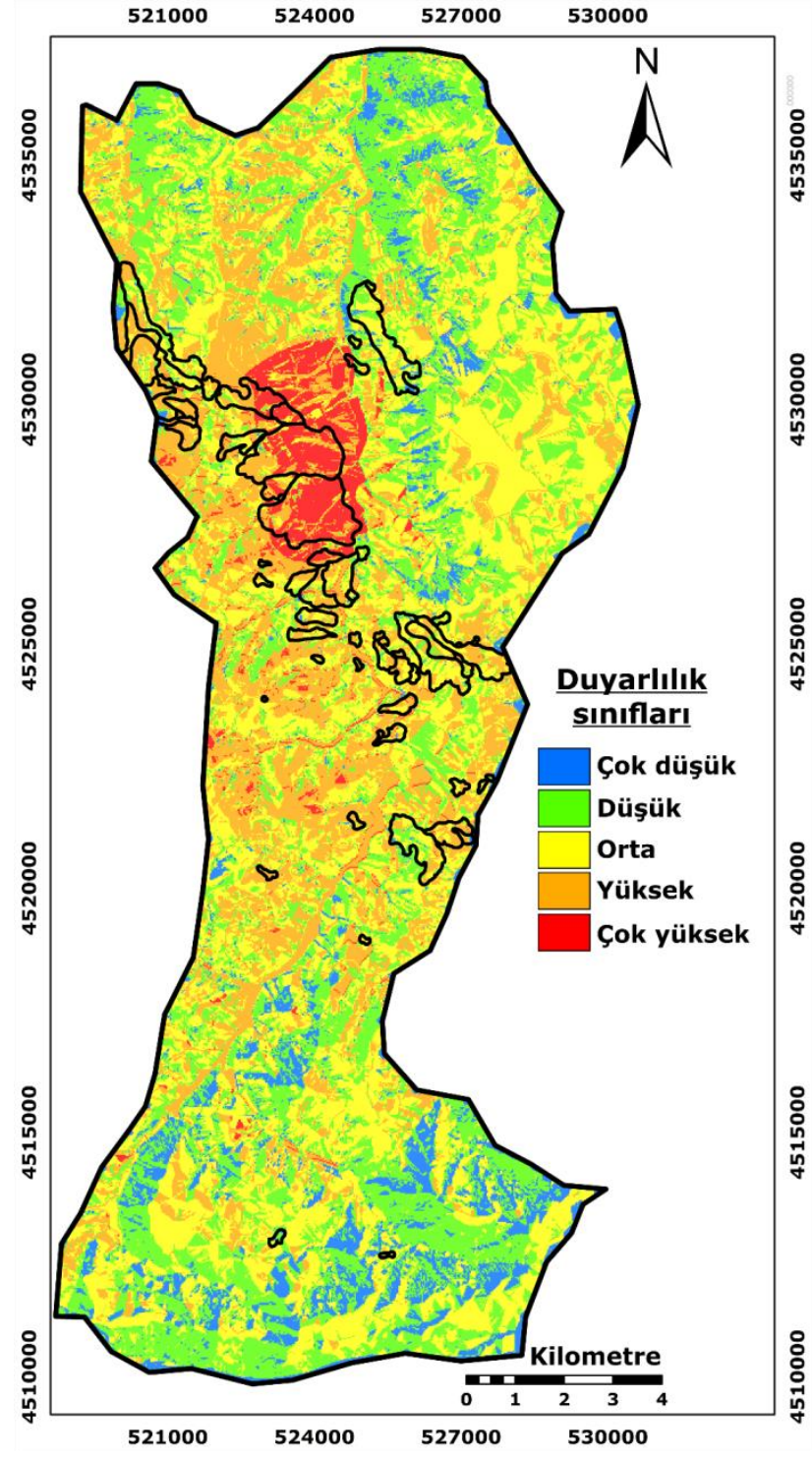

Şekil 6. BURT modeli yardımıyla Tonya ilçesi için üretilen heyelan duyarlılık haritası.

\section{Sonuçlar ve Tartışma}

BURT yaklaşımı ile üretilen heyelan duyarlılık haritasının doğruluk değerlendirmesinin yapılması amacıyla "Eğri Altındaki Alan" (EAA) yöntemi kullanılmıştır. EAA yöntemi, bir olayın meydana gelme ya da gelmeme durumunu güvenli bir biçimde tahmin etme yeteneğini tanımlayarak oluşturulan modelin kalitesini ifade etmektedir (Yeşilnacar ve Topal, 2005; Nandi ve Shakoor, 2009; Y1lmaz, 2010; Akgün ve Türk, 2010). İdeal model, EAA değerinin 1'e yakın olduğu durumu gösterirken, 0.5 'e yakın bir değer, söz konusu modelin doğruluğunun oldukça az olduğunu işaret etmektedir (Fawcett, 2006). EAA yöntemini inceleme alanında uygulamak amaciyla, heyelan oluşmuş ve heyelan oluşmamış alanlardan rastgele seçilen pikseller kullanılarak hazırlanmış temsil edici bir veri seti kullanılmıştır. $\mathrm{Bu}$ işlem sonucuna göre, EAA eğrisinin altında kalan alan BURT yaklaşımı ile üretilen heyelan duyarlılık haritası için 0.72 olarak belirlenmiştir (Şekil 7).

Elde edilen bu EAA değeri uyarınca inceleme alanı için üretilen heyelan duyarlılık haritasının, alandaki duyarlı alanları oldukça başarılı bir şekilde tahmin edebildiği anlaşılmaktadır.

Uluslararası heyelan duyarlılık ile ilgili literatüre bakıldığında, yapay sinir ağları ve bulanık mantık tabanlı yöntemlere dayalı çok sayıda modellemenin olduğu görülmektedir. $\mathrm{Bu}$ yöntemler çoğunlukla "geri yayılımlı ileri besleme (feed forward with back propogation)" tabanl1 yöntemler olup "uyarlamalı sinirsel bulanık çıkarsama sistemleri (ANFIS) gibi bulanık sistemlere dayalı yapay sinir ağı yöntemlerinin de 
son yıllarda kullanıldığı görülmektedir (Sezer vd., 2011; Pradhan, 2013).

$\mathrm{Bu}$ çalışmada, heyelan duyarlılık literatüründe daha önce kullanılmamış, ancak temel mimarisi ve çözüm algoritmaları uyarınca diğer sinir ağ1 yöntemlerine benzerlik gösteren BURT yaklaşımı ilk kez uygulanmıştır. Yararlanılan model ve uygulanan yaklaşımlar itibariyle elde edilen sonucun oldukça kullanılabilir ve kabul edilebilir olduğu görülmektedir. Dolayısıyla, BURT yaklaşımı ile üretilen heyelan duyarlılık haritası, mekânsal planlama ve karar verme süreçlerinde karar vericiler tarafindan kullanılabilir nitelikte görülmektedir.

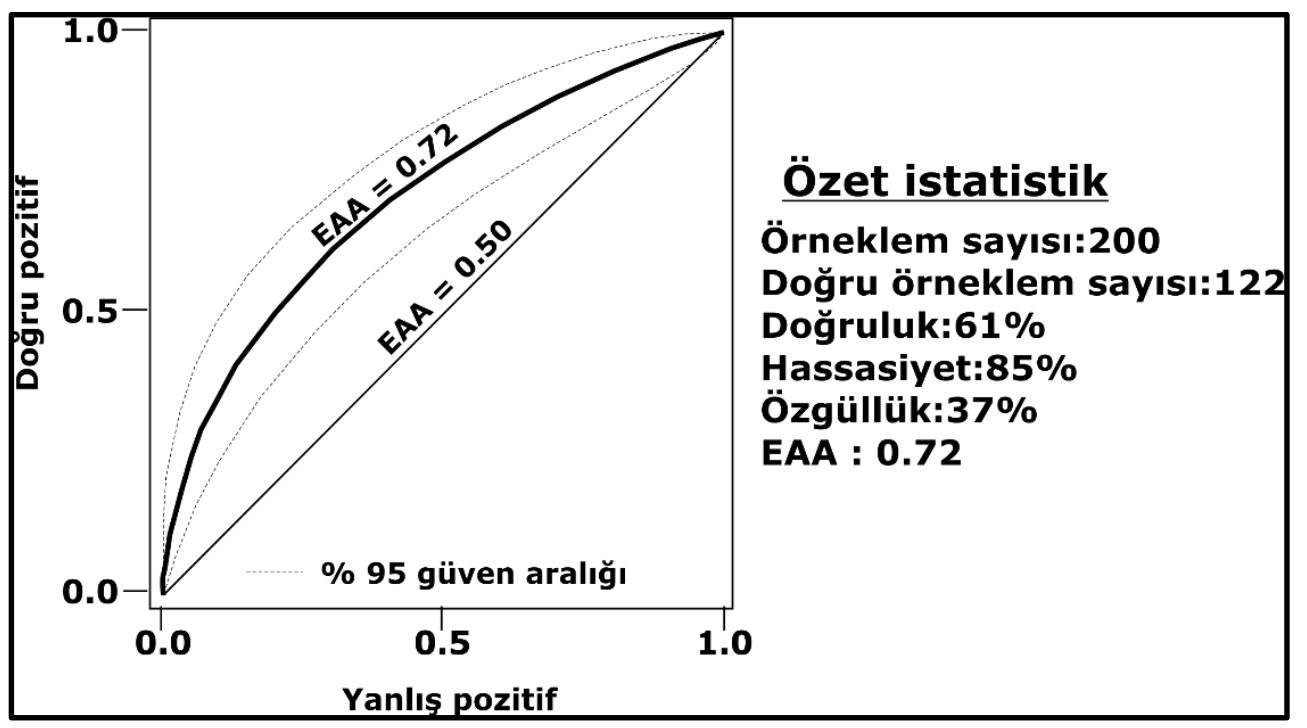

Şekil 7. BURT yaklaşımı ile üretilen heyelan duyarlılık haritasına ait EAA yöntemiyle doğruluk değerlendirmesi.

\section{Kaynaklar}

Akgün, A. ve Bulut, F., (2007). GIS-based landslide susceptibility for Arsin-Yomra (Trabzon, North Turkey) region, Environmental Geology, 51, 1377-1387.

Akgün, A. ve Erkan, O., 2016. Landslide susceptibility mapping by geographical information systems-based multivariate statistical and deterministic models: In an artificial reservoir area at Northern Turkey, Arabian Journal of Geosciences, 9,165,115.

Akgün, A. ve Türk, N., 2010. İki ve Çok Değişkenli İstatistik ve Sezgisel Tabanlı Heyelan Duyarlilik Modellerinin Karşılaştırılması: Ayvalık (Balıkesir, Kuzeybat1 Türkiye) Örneği, Jeoloji Mühendisliği Dergisi, 34(2), 85-112.

Akgün, A., 2012. A comparison of landslide susceptibility maps produced by logistic regression, multicriteria decision and likelihood ratio methods: case study at Izmir, Turkey, Landslides, 9(1), 93-106.

Akgün, A., Sezer E.A., Nefeslioglu, H.A., Gökçeoğlu, C. ve Pradhan, B., 2012. An easy-to-use MATLAB program (MamLand) for the assessment of landslide susceptibility using a Mamdani fuzzy algorithm, Computers and Geosciences, 38(1), 23-34.

Althuwaynee, O.F., Pradhan B, ve Lee, S., 2012. Application of an evidential belief function model in landslide susceptibility mapping, Computers and Geosciences, 44, 120-135.

Carpenter, G. A., 1989. Neural Network Models for Pattern Recognition and Associative Memory, Neural Networks, 2, 243-257.

Carpenter, G. A., Grossberg, S., Markuzon, N., Reynolds, J. H., ve Rosen, D. B., 1992. Fuzzy ARTMAP: A Neural Network Architecture for Incremental Supervised Learning of Analog Multidimensional Maps, IEEE Transactions on Neural Networks, 3(5), 698-713. 
Carpenter, G. A., Grossberg, S., ve Reynolds, J. H., 1991. ARTMAP: Supervised Real-Time Learning and Classification of Nonstationary Data by a Self-Organizing Neural Network, Neural Networks, 4, 565588.

Carrara, A., Cardinali, M., Guzzetti, F. ve Reichenbach, P. 1995, GIS technology in mapping landslide hazard. Carrara, A. and Guzzetti, F (eds.), Geographical Information Systems in assessing natural hazards, Dordrecht: Kluwer. pp.135-175.

Castellanos Abella, E.A. ve Van Westen, C.J., 2007. Generation of a landslide risk index map for Cuba using spatial multi-criteria evaluation, Landslides, 4, 311-325.

Chacon, J., Irigaray, C., Fernandez, T. ve El Hamdouni, R., 2006. Engineering geology maps: landslides and geographical information systems, Bulletin of Engineering Geology and Environment, 65, 341-411.

Çan, T., Nefeslioğlu, H.A., Gökçeoğlu, C., Sönmez, H. ve Duman, T.Y., 2005. Susceptibility assessment of shallow earthflows triggered by heavy rainfall at three subcatchments by logistic regression analyses, Geomorphology, 72, 250-271.

Çevik, E. ve Topal, T., 2003. GIS-based landslide susceptibility mapping for a problematic segment of the natural gas pipeline, Hendek (Turkey), Environmental Geology, 44, 949962.

Çölkesen, I., Kutluğ Sahin, E. ve Kavzoglu, T., 2016. Susceptibility Mapping of Shallow Landslides Using Kernel-Based Gaussian Process, Support Vector Machines and Logistic Regression, Journal of African Earth Sciences, 118, 53-64.

Dağ, S., Bulut, F., Alemdağ, S. ve Kaya, A., 2011. Heyelan Duyarlıl1k Haritalarının Üretilmesinde Kullanılan Yöntem ve Parametrelere İlişkin Genel Bir Değerlendirme, Gümüşhane Üniversitesi Fen Bilimleri Enstitüsü Dergisi,1, 2, 151176.

Dağdelenler G., Nefeslioğlu H.A. ve Gökçeoğlu C., 2016. Modification of seed cell sampling strategy for landslide susceptibility mapping: an application from the Eastern part of the Gallipoli Peninsula
(Canakkale, Turkey), Bulletin of Engineering Geology and the Environment, $75,575-590$.

Demir, G., Aytekin,M., Akgün, A., İkizler, S.B. ve Tatar, O., 2013. A comparison of landslide susceptibility mapping of the eastern part of the North Anatolian fault zone (Turkey) by likelihood-frequency ratio and analytic hierarchy process methods, Natural Hazards, 65,1481-1506.

Duman, T. Y., Nefeslioğlu, H.A.., Çan, T., Olgun, Ş., Durmaz, S., Hamzaçebi, S. ve Çörekçioğlu, Ş., 2007. 1:500.000 Ölçekli Türkiye Heyelan envanter Haritası, Trabzon Paftas1, MTA Özel Yayın Serisi-9.

Eker, A.M., Dikmen, M., Cambazoğlu, S., Düzgün, H.S.B. ve Akgün, H., 2015. Evaluation and Comparison of Landslide Susceptibility Mapping Methods: A Case Study for the Ulus District, Bartın, Northern Turkey, International Journal of Geographical Information Science, 29, 132158.

Ercanoğlu, M. ve Gökçeoğlu, C., 2002. Assessment of landslide susceptibility for a landslide-prone area (north of Yenice, NW Turkey) by fuzzy approach, Environmental Geology, 41, 720-730.

Ercanoğlu, M., Dağdelenler, G., Özsayın, E., Alkevli, T., Sönmez, H., Özyurt, N. N., Kahraman, B., Uçar, İ. ve Çetinkaya, S., 2016. Application of Chebyshev theorem to data preparation in landslide susceptibility mapping studies: an example from Yenice (Karabük, Turkey) region, Journal of Mountain Sciences, 13, 1923-1940.

Erener, A., Mutlu, A. ve Düzgün, H,S., 2016. A comparative study for landslide susceptibility mapping using GIS-based multi-criteria decision analysis (MCDA), logistic regression (LR) and association rule mining (ARM), Engineering Geology, 203, 45-55.

Fawcett,T., 2006. An introduction to ROC analysis, Pattern Recognition Letters, 27, 861- 874.

Gökçeoğlu, C. ve Aksoy, H., 1996. Landslide susceptibility mapping of the slopes in the residual soils of the Mengen region (Turkey) by deterministic stability analyses 
and image processing techniques, Engineering Geology, 44, 147-161.

Gökçeoğlu, C. ve Ercanoglu, M., 2001. Heyelan duyarlılık haritalarının hazırlanmasında kullanılan parametrelere ilişkin belirsizlikler, Yerbilimleri, 23, 189-206.

Guantanamo, Cuba, Computers and Geosciences, 37, 410-425.

Gurocak, Z., Alemdag, S., Bostanci, H.T., ve Gokceoglu, C., 2017. Discontinuity controlled slope failure zoning for a granitoidcomplex: A fuzzy approach.Rock Mechanics and Engineering, Volume 5: Surfaceand Underground Projects, CRC Press Taylor \& Francis Group, eBook ISBN: 978-1-317-48188-1, Pages 1-25.

Guzetti, F., Carrarra, A., Cardinali, M. ve Reichenbach, P., 1999. Landslide hazard evaluation: a review of current techniques and their application in a multiscale study, Central Italy, Geomorphology, 31, 181-216.

Ildır, B. 1995. Türkiye'de heyelanların dagılımı ve afetler yasası ile ilgili uygulamalar. Onalp A (ed) 2. Ulusal Heyelan Sempozyumu, Sakarya Üniversitesi, Türkiye, pp 1-9.

Kavzoğlu, T., Şahin, E.K., ve Çölkesen, I.,2014. Landslide susceptibility mapping using GIS-based multi-criteria decision analysis, support vector machines, and logistic regression, Landslides, 11(3), 425-439.

Kıncal, C., Akgün, A. ve Koca, M.Y., 2009. Landslide susceptibility assessment in the Izmir (West Anatolia,Turkey) city center and its near vicinity by the logistic regression method, Environmental Earth Sciences, 59, 745-756.

Lee, S., Choi, J. ve Min, K., 2004. Landslide hazard mapping using GIS and remote sensing data at Boun, Korea, International Journal of Remote Sensing, 25, 2037-2052.

M.T.A.,1998. 1:100.000 ölçekli Jeoloji Haritaları, Trabzon F42 Paftas1, M.T.A. Yayınları, Ankara.

Mannan, B. ve Roy, J., 1998. Fuzzy ARTMAP supervised classification of multi-spectral remotely-sensed images, International Journal of Remote Sensing, 19, 767-774.
Melchiorre, C., Castellanos, E.A. Van Westen, C.J. ve Matteucci, M., 2011. Evaluation of prediction capability, robustness and sensitivity in non linear landslide susceptibility models,

Moore, I.D., Grayson, R.B. ve Ladson, A.R., 1991. Digital terrain modeling: a review of hydrological, geomorphological and biological applications, Hydrological Processes, 5, 3-30.

Nandi, A. ve Shakoor, A., 2009. A GIS-based landslide susceptibility evaluation using bivariate and multivariate statistical analyses, Engineering Geology, 110, 1120.

Nefeslioğlu H.A., Sezer E.A., Gökçeoğlu, C. ve Ayaş, Z., 2013. A modified analytical hierarchy process (M-AHP) approach for decision support systems in natural hazard assessments, Computers and Geosciences, $59,1-8$.

Nefeslioğlu, H.A., Duman, T.Y. ve Durmaz, S., 2008. Landslide susceptibility mapping for a part of tectonic Kelkit Valley (Eastern Black Sea region of Turkey), Geomorphology, 94, 401-418.

Nefeslioğlu, H.A., Sezer,E., Gökçeoğlu, C., Bozkır, A.S.ve Duman, T.Y., 2010. Assessment of Landslide Susceptibility by Decision Trees in the Metropolitan Area of İstanbul, Turkey, Mathematical Problems in Engineering, 2010, 1-15.

Ösna, T., Sezer E.A. ve Akgün, A., 2014. GEOFIS: an integrated tool for the assessment of landslide susceptibility, Computers and Geosciences, 66, 20-30.

Pradhan, B., 2011. Manifestation of an advanced fuzzy logic model coupled with geoinformation techniques for landslide susceptibility analysis, Environmental and Ecological Statistics, 18, 471-493.

Pradhan, B., 2013. A comparative study on the predictive ability of the decision tree, support vector machine and neuro-fuzzy models in landslide susceptibility mapping using GIS, Computers and Geoscience, 51, 350-365.

Pradhan, B., Sezer, E.A., Gökçeoğlu, C. ve Buchroithner, M.F., 2010. Landslide susceptibility mapping by neuro-fuzzy 
approach in a landslide prone area (Cameron Highland, Malaysia), IEEE Transactions on Geosciences Remote Sensing, 48,4164-4177

Romer, C. ve Ferentinou, M., 2016. Shallow landslide susceptibility assessment in a semiarid environment-A Quaternary catchment of KwaZulu-Natal, South Africa, Engineering Geology, 201, 29-44.

Roodposhti, M.S., Rahimi, S. ve Beglou, M.J., 2013. PROMETHEE II and fuzzy AHP: an enhanced GIS-based landslide susceptibility mapping, Natural Hazards, 73, 77-95.

Sezer, E.A., Pradhan, B. ve Gökçeoğlu, C., 2011. Manifestation of an adaptive neuro-fuzzy model on landslide susceptibility mapping: Klang valley, Malaysia, Expert Systems and Applications, 38, 8208-8219.

Süzen, M.L. ve Doyuran, V., 2004. Data driven bivariate landslide susceptibility assessment using geographical information systems: a method and application to Asarsuyu Catchment, Turkey, Engineering Geology, 71, 303-321.

Thiebes, B., 2011, Landslide analysis and early warning - local and regional case study in the Swabian Alb. Doktora Tezi, University of Vienna, Vienna, 295s.
URL-1,www.meteor.gov.tr. 25 Eylül 2017

USGS, 1993., Data user guide 5 for DEM's. $\mathrm{ftp}: / /$ mapping.usgs.gov/pub/ti/DEM/demgui de.

Varnes, D.J., 1978, Slope movement types and processes. Landslides Analysis and Control. Special Report. Schuster, R.L., Krizek, R.J. (eds.), National Academy of Sciences, New York. pp. 12- 33.

Yeşilnacar, E. ve Topal, T., 2005. Landslide susceptibility mapping: A comparision of logistic regression and neural networks methods in a medium scale study, Hendek region (Turkey), Engineering Geology, 79, 251-266.

Y1lmaz, I., 2009. A case study from Koyulhisar (Sivas-Turkey) for landslide susceptibility mapping by Artificial Neural Networks, Bulletin of Engineering Geology and the Environment, 68 (3), 297-306.

Y1lmaz, I., 2010. Comparison of landslide susceptibility mapping methodologies for Koyulhisar, Turkey: Conditional Probability, Logistic Regression, Artificial Neural Networks, and Support Vector Machine, Environmental Earth Sciences, 61, 821-836. 